\title{
O ACESSO À CIDADE NEGADO PELA PRODUÇÃO CAPITALISTA DO ESPAÇO NA CIDADE DE CRUZEIRO-SP
}

\author{
Tamyse Campos Bueno Norberto ${ }^{1}$ \\ Paulo Romano Reschilian²
}

Resumo: A cidade é um produto histórico e social resultado da transformação do homem na natureza. Assim, a cidade é o espaço no qual a sociedade estabelece relações e que se modifica à medida em que o território se transforma. A produção do espaço é balizada pela acumulação do capital que resulta em conseqüências para a realização da vida humana debruçada na desigualdade social e acesso à cidade para parte da população apenas. As práticas de planejamentos que foram tomados como caminhos para organizar este organismo complexo que é a cidade desde o início do século passado, hoje, mostram-se incompletos. Cruzeiro-SP, cidade pequena (segundo classificação do IBGE) do fundo do Vale do Paraíba apresenta uma produção do espaço constituída das mesmas características das cidades medias e de grande porte baseada no espraiamento da cidade e segregação sócioespacial.

Palavras-chave: Espraiamento da cidade; Segregação sócioespacial; Acumulação do capital; Produção do espaço.

\footnotetext{
1 Instituto de Pesquisa e Desenvolvimento/Universidade do Vale do Paraíba, Brasil. E-mail: tamyasecampos@gmail.com.

2 Instituto de Pesquisa e Desenvolvimento/Universidade do Vale do Paraíba, Brasil. E-mail: pauloromano@univap.br.
} 